Endocrinol. Japon. 1967, 14 (2), 178 181

\title{
THE TIMING OF THE KOROTKOFF SOUNDS: A MEASURE OF HYPERTHYROIDISM
}

\author{
TAKuo FUJITA AND MASAKI YOSHIKAWA \\ Department of Geriatrics, Faculty of Medicine, University of Tokyo, Tokyo \\ KUNIHIKo ITO, TAKUYA SUZUKI \\ Ito Hospital, Tokyo \\ SIMON RODBARD \\ City of Hope Medical Center Duarte, California, U.S.A.
}

\section{SYNOPSIS}

The interval between the onsets of the ORS complex and of the brachial Korotkoff sounds at the diastolic pressure in 23 cases of hyperthyroidism was 'distinctly shorter, $0.15 \pm 0.002 \mathrm{sec}(\mathrm{SE})$, than the interval of $0.21 \pm 0.004 \mathrm{sec}$ obtained in euthyroid subjects. Measurement of this interval offers a simple, safe, rapidly obtained index of thyroid function.

The timing of the Korotkoff sounds in the cardiac cycle is of value in the study of various cardiovascular abnormalities. (Rodbard et al. 1957 and 1965) In patients with hypothyroidism, the interval between the onsets of the electrical activity of the heart and of the arterial sounds of Korotkoff at the brachial artery is abnormally prolonged. (Rodbard et al. 1966) The time of onset of the Korotkoff sounds in the cardiac cycle was therefore examined in patients with hyperthyroidism.

\section{MATERIALS}

Studies were performed on 23 hyperthyroid subjects and 23 clinically euthyroid subjects, with ages ranging from 23 to 70 years. The measurements were performed at the Ito Hospital of Tokyo, or at the Department of Geriatrics, University of Tokyo.

\section{METHODS}

The patient was comfortably recumbent. Electrocardiographic leads of a phonocardio- graphic machine were connected to the four limbs to provide a time reference. A sphygmomanometer cuff on the upper arm inflated to a pressure higher than the systolic pressure was allowed to deflate slowly to a level well below the diastolic pressure. A microphone placed lightly over the brachial artery transmitted the acoustic signal to the second channel of the recorder. Each $10 \mathrm{~mm} \mathrm{Hg}$ fall in cuff pressure was marked by the introduction of standardization impulses into the electrocardiogram; a double standardization marked the $100 \mathrm{~mm} \mathrm{Hg}$ level. The time from the onset of the QRS complex (Q) to the onset of the Korotkoff (K) was termed the QK interval. The interval at the systolic (s) pressure was designated as QKs; the interval at the diastolic (d) pressure was designated as QKd. The difference between QKs and QKd was listed as QKs-d and designated as the rise time (T) of the arterial pressure wave. Pulse pressure (P) was divided by $T$ to give the mean rate of pressure rise, $P / T$.

\section{RESULTS}

Tables 1 and 2 demonstrate that patients

Received for publication April 20, 1967. 
Table 1. Korotkoff sounds in hyperthyroidism

\begin{tabular}{|c|c|c|c|c|c|c|c|c|c|c|c|c|c|}
\hline \multirow[b]{2}{*}{ Initials } & \multirow[b]{2}{*}{ Age } & \multirow[b]{2}{*}{ Sex } & \multicolumn{3}{|c|}{$\begin{array}{c}\text { Arterial Pressure } \\
\mathrm{mm} \mathrm{Hg}\end{array}$} & \multicolumn{3}{|c|}{$\begin{array}{c}\text { Korotkoff } \\
\text { Interval secs. }\end{array}$} & \multirow{2}{*}{$\frac{\mathrm{P} / \mathrm{T}}{\mathrm{mm} \mathrm{Hg}}$} & \multirow{2}{*}{$\underset{\%}{\mathrm{BMR}}$} & \multirow[t]{2}{*}{ RAIU } & \multirow[t]{2}{*}{$\begin{array}{l}\text { PBI } \\
\gamma / \mathrm{m} l\end{array}$} & \multirow{2}{*}{$\begin{array}{c}\text { Resin } \\
\text { Sponge } \\
\text { Uptake } \\
\%\end{array}$} \\
\hline & & & $\begin{array}{l}\text { Systo- } \\
\text { lic }\end{array}$ & $\begin{array}{l}\text { Dia- } \\
\text { stolic }\end{array}$ & $\underset{\text { Pulse }}{\text { Pu }}$ & QKs & QKd & $\underset{(\mathrm{T})}{\mathrm{QKs-d}}$ & & & & & \\
\hline MH & 75 & $F$ & 138 & 65 & 73 & .34 & .16 & .18 & 4.0 & +50 & & & 61 \\
\hline $\mathrm{TH}$ & 57 & $\mathbf{M}$ & 120 & 85 & 35 & .19 & .13 & .06 & 5.8 & +88 & & & 59 \\
\hline $\mathrm{MT}$ & 48 & $\mathrm{~F}$ & 112 & 15 & 97 & .22 & .13 & .09 & 10.8 & & & & \\
\hline HT & 46 & $\mathrm{~F}$ & 124 & 15 & 109 & .32 & .15 & .17 & 6.4 & +56 & & & \\
\hline $\mathrm{RS}$ & 42 & $\mathrm{~F}$ & 165 & 90 & 75 & .25 & .15 & .10 & 7.5 & +73 & 72 & 5.5 & \\
\hline MW & 41 & $\mathrm{~F}$ & 165 & 55 & 110 & .37 & .15 & .22 & 5.0 & +61 & & & \\
\hline RS & 38 & $\mathrm{~F}$ & 130 & 40 & 90 & .25 & .15 & .10 & 9.0 & +96 & 76 & 8.4 & \\
\hline FA & 33 & $\mathrm{~F}$ & 155 & 25 & 130 & .24 & .14 & .10 & 13.0 & +58 & & & 39 \\
\hline $\mathrm{HA}$ & 33 & M & 156 & 10 & 146 & .27 & .14 & .13 & 11.2 & +43 & & & 40 \\
\hline $\mathrm{TI}$ & 31 & $F$ & 120 & 58 & 62 & .23 & .16 & .07 & 8.9 & +110 & & & 56 \\
\hline MH & 31 & M & 135 & 30 & 105 & .28 & .16 & .12 & 8.8 & +69 & & 13.9 & \\
\hline MK & 30 & $\mathrm{~F}$ & 144 & 74 & 70 & .23 & .15 & .08 & 8.8 & +75 & & & \\
\hline $\mathrm{MT}$ & 30 & $\mathrm{~F}$ & 128 & 82 & 46 & .35 & .17 & .18 & 2.6 & +47 & & & \\
\hline TK & 29 & M & 140 & 12 & 128 & .25 & .15 & .10 & 12.8 & +75 & 59 & 14.3 & \\
\hline $\mathrm{KU}$ & 27 & $\mathrm{~F}$ & 126 & 32 & 94 & .28 & .13 & .15 & 6.3 & +43 & & & \\
\hline $\mathrm{HI}$ & 26 & $F$ & 138 & 10 & 128 & .30 & .14 & .16 & 8.0 & +37 & 75 & & 56 \\
\hline SM & 25 & $\mathrm{~F}$ & 132 & 20 & 112 & .26 & .15 & .11 & 10.2 & +34 & 51 & & \\
\hline SO & 25 & $\mathrm{~F}$ & 120 & 60 & 60 & .27 & .15 & .12 & 5.0 & +72 & & & 58 \\
\hline $\mathrm{AO}$ & 25 & $\mathrm{~F}$ & 129 & 48 & 81 & .29 & .16 & .13 & 6.2 & +25 & & & \\
\hline $\mathrm{KE}$ & 23 & $\mathrm{~F}$ & 140 & 75 & 65 & .31 & .16 & .15 & 4.3 & +80 & & 16.3 & 50 \\
\hline $\mathrm{SH}$ & 23 & $\mathrm{M}$ & 155 & 30 & 125 & .28 & .15 & .13 & 9.6 & +105 & & 20.0 & 53 \\
\hline $\mathrm{KF}$ & 23 & $\mathbf{M}$ & 124 & 42 & 82 & .30 & .16 & .14 & 5.8 & +54 & & & 34 \\
\hline HS & 22 & $\mathrm{M}$ & 143 & 25 & 118 & .27 & .16 & .11 & 10.7 & +75 & 59 & 14.3 & \\
\hline Average & 34 & $\begin{array}{c}7 \mathrm{M} \\
16 \mathrm{~F}\end{array}$ & $136 \pm 3^{*}$ & $43 \pm 5^{*}$ & $96 \pm 6^{*}$ & $\begin{array}{r}.28 \\
\pm .009 \\
\end{array}$ & $\begin{array}{r}.15^{*} \\
\pm .002 \\
\end{array}$ & $\begin{array}{r}.13 \\
\pm .008 \\
\end{array}$ & $\begin{array}{r}7.8^{*} \\
\pm 0.6 \\
\end{array}$ & & & & \\
\hline
\end{tabular}

${ }^{*} \mathrm{P}<0.01$ from Euthyroid Subjects.

with hyperthyroidism had higher systolic and pulse pressures, and lower diastolic pressures than were found in euthyroid subjects of the control group. QKd was shorter in hyperthyroid subjects than in euthyroid controls. QKs and QKs-d did not discriminate between euthyroid and hyperthyroid subjects. The mean rate of pressure rise, $\mathrm{P} / \mathrm{T}$, was greater in the hyperthyroid patients than in the euthyroid subjects. BMR and QKd in the hyperthyroid subjects were not correleated (Fig. 1).

\section{DISCUSSION}

The QKd time is the sum of a chain of physiological intervals including the time required for ventricular depolarization, mobilization of myocardial tension, and elevation of pressure sufficient to equal the systemic arterial diastolic pressure and to open the aortic valve, and the interval required for transmission of the pressure wave from the aortic valve to the recording site. The interval from the onset of electrical activity in the ventricle until the aortic valves open is normally about $0.07 \mathrm{sec}$. The time required for the arterial pressure wave to pass from the aortic valve to the cuff and to generate a sound may be considered to account for the remainder of the $\mathrm{QKd}$ interval.

It has long been known that the heart is very sensitive to circulating thyroid hormones. 
Table 2. Korotkoff sound in euthyroid subjects

\begin{tabular}{|c|c|c|c|c|c|c|c|c|c|}
\hline \multirow[b]{2}{*}{ Initials } & \multirow[b]{2}{*}{ Age } & \multirow[b]{2}{*}{ Sex } & \multicolumn{2}{|c|}{ Arterial Pressure } & \multirow{2}{*}{$\frac{\mathrm{mm} \mathrm{Hg}}{\text { Pulse(P) }}$} & \multicolumn{3}{|c|}{ Korotkoff Interval (sec.) } & \multirow{2}{*}{$\begin{array}{c}\mathrm{P} / \mathrm{T} \\
\mathrm{mm} \mathrm{Hg} \\
0.01 \mathrm{sec} .\end{array}$} \\
\hline & & & Systolic & Diastolic & & QKs & QKd & $\begin{array}{l}\text { QKs-d } \\
(\mathrm{T})\end{array}$ & \\
\hline $\mathrm{TA}$ & 65 & $M$ & 160 & 110 & 50 & .36 & .21 & .15 & 3.3 \\
\hline TO & 58 & $\mathbf{M}$ & 110 & 85 & 25 & .36 & .24 & .12 & 2.1 \\
\hline $\mathrm{HN}$ & 48 & $\mathbf{M}$ & 146 & 85 & 61 & .33 & .21 & .12 & 5.1 \\
\hline SI & 46 & M & 110 & 72 & 38 & .30 & .20 & .10 & 3.8 \\
\hline MI & 44 & M & 95 & 76 & 19 & .28 & .22 & .06 & 3.2 \\
\hline SK & 42 & $\mathrm{~F}$ & 75 & 50 & 25 & .28 & .21 & .07 & 3.6 \\
\hline TM & 39 & M & 130 & 60 & 70 & .31 & .20 & .11 & 6.4 \\
\hline TS & 38 & M & 124 & 72 & 52 & .30 & .20 & .10 & 5.2 \\
\hline YI & 38 & $M$ & 95 & 53 & 42 & .27 & .20 & .07 & 6.0 \\
\hline TF & 36 & M & 108 & 78 & 30 & .34 & .24 & .10 & 3.0 \\
\hline YE & 35 & M & 95 & 50 & 45 & .30 & .20 & .10 & 4.5 \\
\hline TS & 35 & M & 127 & 72 & 55 & .32 & .18 & .14 & 3.9 \\
\hline TO & 33 & $F$ & 98 & 68 & 30 & .32 & .23 & .09 & 3.3 \\
\hline MI & 33 & $\mathrm{~F}$ & 120 & 78 & 42 & .30 & .22 & .08 & 5.2 \\
\hline MI & 33 & $M$ & 124 & 72 & 52 & .30 & .20 & .10 & 5.2 \\
\hline KT & 32 & $M$ & 112 & 60 & 52 & .32 & .20 & .12 & 4.3 \\
\hline $\mathrm{KH}$ & 32 & M & 142 & 78 & 64 & .30 & .18 & .12 & 5.3 \\
\hline SH & 31 & M & 118 & 75 & 43 & .32 & .22 & .10 & 4.3 \\
\hline MS & 29 & $F$ & 140 & 115 & 25 & .28 & .22 & .06 & 4.2 \\
\hline $\mathrm{KI}$ & 26 & $F$ & 114 & 25 & 89 & .34 & .22 & .12 & 7.4 \\
\hline YK & 26 & $\mathrm{~F}$ & 108 & 72 & 36 & .37 & .22 & .15 & 2.4 \\
\hline $\begin{array}{l}\text { SM } \\
\text { NT }\end{array}$ & $\begin{array}{l}24 \\
23\end{array}$ & $\begin{array}{l}\mathrm{F} \\
\mathrm{F}\end{array}$ & $\begin{array}{r}115 \\
97\end{array}$ & $\begin{array}{l}55 \\
55\end{array}$ & $\begin{array}{l}60 \\
42\end{array}$ & $\begin{array}{l}.32 \\
.32\end{array}$ & $\begin{array}{l}.20 \\
.22\end{array}$ & $\begin{array}{l}.12 \\
.10\end{array}$ & $\begin{array}{l}5.0 \\
4.2\end{array}$ \\
\hline Average & 37 & $\begin{array}{c}15 \mathrm{M} \\
8 \mathrm{~F}\end{array}$ & $116 \pm 4$ & $70 \pm 4$ & $46 \pm 3$ & $\begin{array}{r}.31 \\
\pm .006\end{array}$ & $\begin{array}{r}.21 \\
\pm .004\end{array}$ & $\begin{array}{r}.10 \\
\pm .005\end{array}$ & $\begin{array}{r}4.4 \\
\pm 0.3\end{array}$ \\
\hline
\end{tabular}

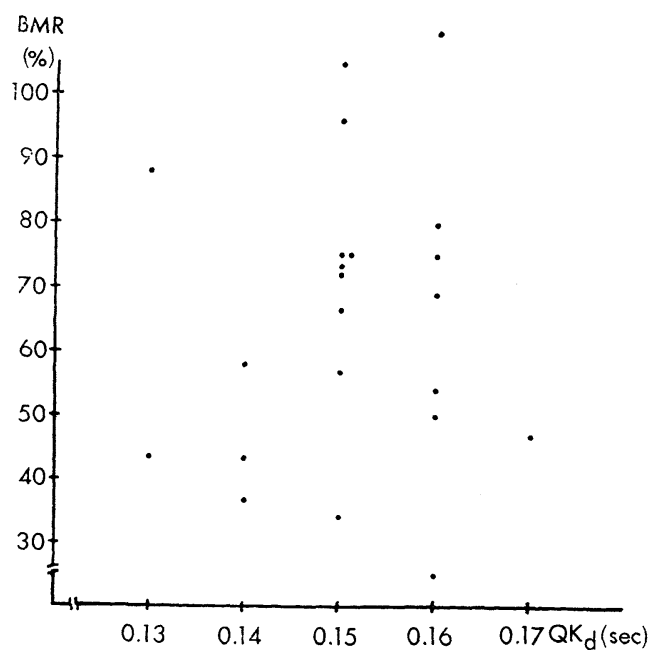

Fig. 1. BMR and QKd in Hyperthyroidism
Recently it has been found that the sinus node takes up thyroid hormone selectively (Tommaselli et al., 1965). Thyroid hormones can increase the heart rate and probably increase the rate of mobilization of myocardial tension, (Brewster et al., 1958) accelerating the rise in ventricular pressure. It is possible that when the rate of mobilization of ventricular tension is increased, the velocity of the pulse wave is accelerated. This conclusion is suggested by the shortening of the QKd interval by as much as $0.07 \mathrm{sec}$ in hyperthyroidism. Some of the shortening of the QKd interval must therefore be due to a reduction in the time required for transmission of the pressure wave from the aortic valve to the cuff.

Complete separation of QKd values in the two groups of subjects in the present 
experiment suggests that this measure may be useful in evaluating the state of excessive thyroid activity. Thus, all hyperthyroid subjects showed QKd values less than $0.17 \mathrm{sec}$ while all euthyroid subjects showed QKd values of $0.18 \mathrm{sec}$ or longer. Evidence has been presented previously that hypothyroid states are associated with prolongation of the QKd (Rodbard et al., 1966). In view of the QKd values of $0.16 \pm 0.01$ in another group of 10 patients with milder hyperthyroidism with BMR of $30 \pm 4 \%$, occurence of borderline $\mathrm{QKd}$ values is quite conceivable.

The mean rate of rise of the arterial pressure, $P / T$, was also significantly higher in hyperthyroidism than in euthyroidism, although there was considerable overlap of values obtained on hyper-and euthyroid subjects.

The absence of a readily recognizable correlation between QKd and basal metabolic rate, $\mathrm{BMR}$, suggests that these two estimates of thyroid hyperactivity may represent somewhat different manifestations of the disease.

The measurement of QKd appears to offer a useful estimate of thyroid function. Thus, preparation of the patient by fasting or sedation is not necessary, previous intake of iodine need not be considered, venipuncture is unnecessary, and the use of in vivo or in vitro radioiodine is not required. This safe, rapid test may offer some clinical advantages for the estimation of thyroid function, although conditions with high cardiac output such as anemia, fever, and post-exercise state could give false positive results.

\section{ACKNOWLEDGEMENT}

The cooperation of Drs. Hajime Orimo and Masahiro Ohata of the Department of Geriatrics, University of Tokyo Faculty of Medicine is appreciated.

\section{REFERENCES}

Brewster, R. Jr., P. Isaacs, R. Osgood, A.M. Nylander, and Y.W. Chock (1958). Bull. Johns Hopkins Hosp. 103, 157.

Rodbard, S., and R.K. Kramer (1966) Am. J. Med. Sci. 252, 404.

Rodbard, S. and A.J. Libanoff (1965). New Engl. J. Med. 273, 780.

Rodbard, S., H.M. Rubinstein, and S. Rosenblum (1957). Am. Heart. J. 53, 205.

Tommaselli, A., E. Gravina, and J. Roche. Current Topics in Thyroid Disease, Academic Press, New York p. 382 (1965). 